
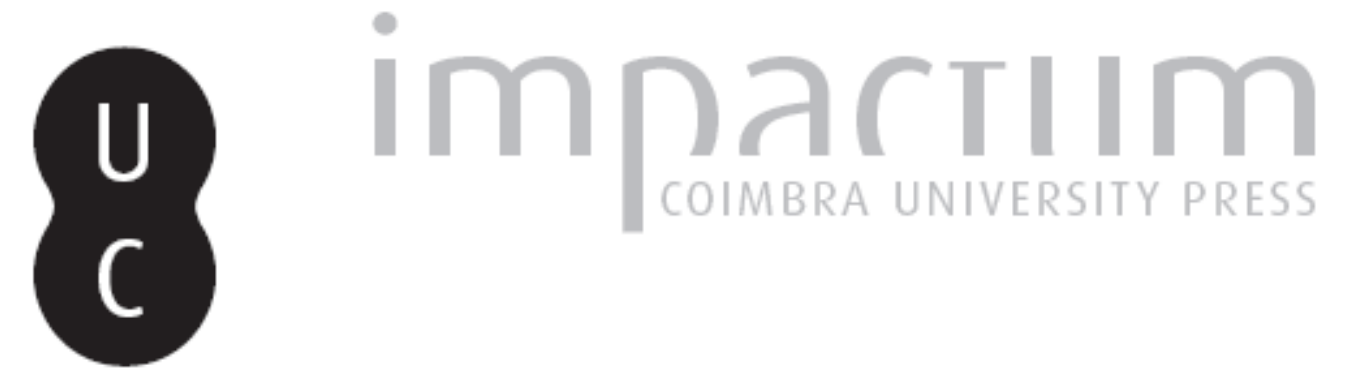

\title{
As ideias cosmopolitas de Marco Aurélio
}

\section{Autor(es): $\quad$ Alves, Sérgio Lourosa}

Publicado por: Centro de História da Universidade de Lisboa

URL persistente:

URI:http://hdl.handle.net/10316.2/23766

DOI:

DOI:http://dx.doi.org/10.14195/0871-9527_20_30

Accessed : $\quad$ 26-Apr-2023 04:22:07

A navegação consulta e descarregamento dos títulos inseridos nas Bibliotecas Digitais UC Digitalis, UC Pombalina e UC Impactum, pressupõem a aceitação plena e sem reservas dos Termos e Condições de Uso destas Bibliotecas Digitais, disponíveis em https://digitalis.uc.pt/pt-pt/termos.

Conforme exposto nos referidos Termos e Condições de Uso, o descarregamento de títulos de acesso restrito requer uma licença válida de autorização devendo o utilizador aceder ao(s) documento(s) a partir de um endereço de IP da instituição detentora da supramencionada licença.

Ao utilizador é apenas permitido o descarregamento para uso pessoal, pelo que o emprego do(s) título(s) descarregado(s) para outro fim, designadamente comercial, carece de autorização do respetivo autor ou editor da obra.

Na medida em que todas as obras da UC Digitalis se encontram protegidas pelo Código do Direito de Autor e Direitos Conexos e demais legislação aplicável, toda a cópia, parcial ou total, deste documento, nos casos em que é legalmente admitida, deverá conter ou fazer-se acompanhar por este aviso.

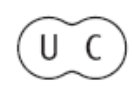




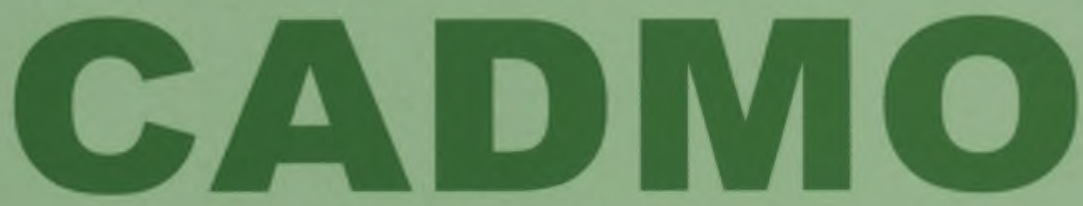

Revista de História Antiga

\author{
Centro de História \\ da Universidade de Lisboa
}

\title{
20
}

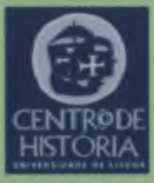

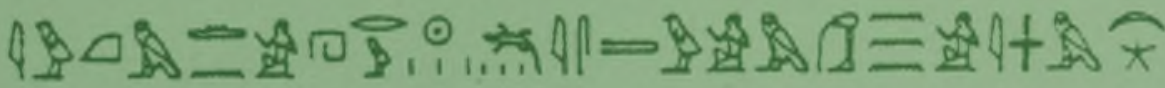

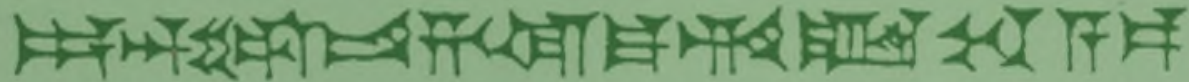

MHNIN AEI $\Delta$ E $\Theta E A ~ \Pi H \Lambda H I A \triangle E \Omega$ 


\title{
AS IDEIAS COSMOPOLITAS DE MARCO AURÉLIO
}

\author{
SÉRGIO LOUROSA ALVES \\ Universidade de Lisboa \\ sergio.ruben.alves@gmail.com
}

\section{Resumo}

As ideias cosmopolitas de Marco Aurélio trazem um valioso contributo para o pensamento político e internacionalista actual. Partindo dos conceitos filosóficos que o imperador-filósofo advoga na sua obra, Pensamentos, compreende-se quais são as implicações políticas da lei natural e natureza universal, da cidadania como natureza normativa do ser racional, da vida em comunidade e da igualdade/«interesse" comum, em contexto imperial. Conclui-se, então, que o cosmopolitismo aureliano continua a estar inserido numa moralidade estóica com pouco realismo político, mas não se pode negar as influências que teve no pensamento liberal, no universalismo kantiano e na política internacionalista contemporânea de globalização.

Palavras-chave: Cosmopolitismo; Pensamentos; Marco Aurélio; Cidadania; Comunidade.

\section{Abstract}

The cosmopolitan ideas of Marcus Aurelius bring a valuable contribution to current political and internationalist thought. Starting from the philosophical concepts that the emperor-philosopher argues in his book, Meditationes, we try to understand the policy implications in imperial context of natural law and universal nature, citizenship as a normative nature of the rational being, community life and equality/common «interest». It leads to the conclusion that Aurelian cosmopolitanism continues to be inserted into a stoic morality with minor political realism, but one can not deny the influence it had on liberal 
thought, in the Kantian universalism and contemporary internationalism politics of globalization.

Key-Words: Cosmopolitanism; Meditationes; Marcus Aurelius; Citizenship; Community.

$\mathrm{Na}$ contemporaneidade, a temática internacionalista está sempre presente no pensamento político, mas muitos desconhecem que já os estóicos tinham formulado o ideal político cosmopolita e a sua respectiva defesa filosófica. Os estóicos acreditavam no conceito de constituição mista, o qual, para os governantes actuais, não traz nenhum contributo ou benefício directo, mas a ambiguidade desta ideia pode ser uma mais-valia para o pensamento político em geral(1). Esta dualidade governativa é somente possível na perspectiva estóica juntando o ideal cosmopolita que funciona como elemento de união. Marco Aurélio, apelidado como o último estóico, não é indiferente a esta questão(2).

O estoicismo, entre todas as escolas filosóficas da. Antiguidade, parece ser a priori a corrente filosófica que menos contribui para um estudo contemporâneo de pensamento político, pois os seus dogmas parecem não ter qualquer relação com as realidades actuais referentes ao poder governativo ou organização social. À questão de quem deve governar, os filósofos estóicos respondem o homem sábio (sophos), sem maior desenvolvimento. Pode referir-se, então, que não teorizam um pensamento político directo e concreto, mas, em relação à vida política, conseguem construir doutrinas de resignação ou oposição. Veja-se o caso da "oposição estóica» de Trásea Peto, Helvídio Prisco, Catão, Díon e Bruto, apresentado por Marco Aurélio(3).

Esta aparente irrelevância do estoicismo no pensamento, realidades ou intervenções políticas, pode ser contrariada através do substancial tema estóico sobre a comunidade ideal ${ }^{(4)}$. Este tópico foi logo avançado por Zenão, fundador da Escola do Pórtico, e encontra um forte desenvolvimento em Marco Aurélio, sobretudo no conceito universalmente válido de lei natural. Ainda assim, esta temática é amplamente discutível e aplicada de uma forma mais comum em contextos utópicos. Tenha-se sempre em consideração os seguintes seis argumentos. Primeiro: o estoicismo é uma das únicas correntes filosóficas antigas que providencia um conceito suficientemente igualitário sobre os seres humanos, potenciando a ideologia liberal. Segundo: o estoicismo investe a cidadania em cada ser normativo e racional por 
natureza. Terceiro: o estoicismo não coloca a justiça ou a lei em instituições, pois estas são essenciais à identidade de cada ser racional. Quarto: a cidadania dos seres racionais não pode ser utilizada para o próprio benefício económico-social, mas deve ser vivida mutuamente por todos. Quinto: o "interesse comum" da lei natural promove uma distribuição igualitária de bens e serviços. E sexto: a distinção estóica entre acções boas e indiferença para com os outros é o exemplo claro que se deve ser o mais racional possível para viver num mundo no qual não se consegue ter um controlo total de tudo(5).

O termo "cosmopolita" é utilizado no sentido grego e o conceito "cidadão do universo" ${ }^{(6)}$ é o elemento de praticabilidade deste pensamento. A tarefa do cidadão é trabalhar da observação à teoria: deve examinar tudo na sua vida e considerar o tipo de universo a que pertence, verificando a função que cada indivíduo exerce e qual o valor do universo (como um todo) e do cidadão (como um cidadão do Estado): «não ignoro e eis porque uso a lei natural com benevolência e justiça [...] Se realizares a tua tarefa presente segundo a razão correcta, com zelo, vigor, bom humor e sem preocupação [...] és capaz da sinceridade heróica, viverás feliz.»"(7).

O cosmopolitismo de Aurélio é positivista quando defende de forma determinada a lei natural e a razão universal, mas é graças a este esforço que hoje em dia ainda se pensa na defesa dos direitos humanos ou na diferenciação de lei internacional (ius gentium) e lei governamental/civil (ius ciuile). O império que Marco Aurélio governava mostrou-lhe a possibilidade da extensão da cidadania a várias províncias, concedendo aos diferentes povos uma identidade que ultrapassava as suas alianças locais. O próprio internacionalismo do Império Romano é um factor marcante e decisivo para o pensamento político mundial.

As ideias cosmopolitas sobreviveram até à contemporaneidade por via do universalismo moral kantiano: teoria da lei natural e indiferença de etnia, género e status dos indivíduos. Actualmente, porém, é importante o legado destas noções ao nível político: instituições internacionais, comércio livre e mundial, luta pela paz mundial e combate contra os regimes opressivos. Tenha-se desde já a visão que o cosmopolita antigo não se tipifica como um indivíduo altamente sofisticado. A principal continuidade entre o cosmopolita antigo e o moderno situa-se na expressão de "cidadão do mundo" que é alargada literal ou metaforicamente, sabendo-se que é impossível existir um estado ou um governo global. A importância permanece nos argumentos que estas ideias cosmopolitas advogaram para todos os seres humanos ${ }^{(8)}$. 


\section{Lei natural e natureza humana/universal}

O estoicismo é a corrente filosófica que mais pormenorizadamente promulga o conceito de lei natural(9). Para esta questão, Marco Aurélio aponta especialmente as inferências do atributo universal da razão humana com a cidadania, comunidade e lei, acreditando que o mundo, visto como um todo, está sob a direcção providencial ou divina (prouidentia deorum), com inteligência benevolente e suprema. Este é o rumo que atribui à lei natural, sempre com um cariz divino e objectivo, envolvendo uma força natural de procura de valores morais e uma relação interdependente de seres racionais.

A natureza universal resulta da união inata da justiça, da lei e da razão. Assim, a razão deriva da natureza, estando também inserida a lei e a justiça como elementos de solidez entre as três ideias. A injustiça, pelo contrário, funciona como factor de desconstrução do ideal cosmopolita. Marco Aurélio esforçou-se por construir uma comunidade de homens ordenados e organizados: "[...] deixam-se, eles também, desorientar por uma aparência da razão. Mas se queres compreender o sentido do que disse, não passes pelo precedente de te afastares de alguma acção útil à sociedade» (10). O dogma da universalidade tem a sua fonte na lei natural, um vector de discurso que aproxima Aurélio do cinismo ${ }^{(11)}$.

Em termos práticos, a filosofia sócio-política do imperador-filósofo estabelece que a lei natural acarreta deveres, e não direitos - "Conserva-te simples, honesto, puro, grave, natural, amigo da justiça, piedoso, benévolo, afectuoso, firme no cumprimento dos deveres"(12) sendo o serviço à sociedade um dever pressuposto na mera existência humana. Segundo as leis da natureza universal, o mundo é um produto da razão, concebendo que a ordem universal provém da experiência humana. As ideias cosmopolitas de Marco Aurélio acabam por ter um cariz antropomórfico, ou antropocêntrico, quando refere que o homem não pode ter uma relação unilateral com o presente, deve igualmente construir uma ligação com o passado e futuro, pois qualquer coisa que aconteça tem que ser determinada pela ordem universal e razão (sinónimos no discurso estóico). Deduzem-se deste modo os seguintes paradoxos da exaltação da razão: fonte de ordem do mundo, regra única e juízo para todas as coisas, fonte exclusiva de bem para todos os seres e, especificamente, medida e origem da moralidade do homem. A razão personifica-se na constituição do homem, tanto nas suas relações com mundo, como nas suas capacidades, objectivos ou 
esperanças. A máxima para se ser um «cidadão do mundo" será: viver de acordo com a natureza é viver de acordo com a razão, pois o homem é um ser moral, se for um ser social ${ }^{(13)}$.

À lei natural junta-se também a noção objectiva de justiça, distinguindo-se a ideologia estóica de igualitarismo liberal e cosmopolitismo. Se tudo é passível de julgamento, toda a falta é, de facto, um falso juízo e um precedente de ignorância. A unidade funciona como uma racionalidade exemplar do mundo, pois o bem deve ser algo idealmente sequencial, contínuo e consequente. Com o elemento da justiça, Aurélio encontra uma via secularizada de entendimento da lei natural, ou seja, não depende somente da providência divina, mas é também um interesse puro e naturalista de todos os homens, da humanidade ${ }^{(14)}$.

A lei natural é optimista por essência, conseguindo até salvaguardar os momentos bélicos por serem do interesse de todos ${ }^{(15)}$. Tudo provém e se dispõe conforme a vontade da natureza universal, incluindo a maldade dos homens, consequência necessária do dom da liberdade. Por fim, tudo acontece em concordância com o destino, no qual todas as coisas se metamorfoseiam sem cessar na ordem do universo, e também se repetem sem parar, pois o homem acabará por morrer: "[...] conta com todos aqueles que depois de se terem guerreado até à morte [...] jazem estendidos no túmulo, reduzidos a cinzas - e acalma-te, enfim!» (16). Quanto mais os estóicos querem definir o conceito de lei natural, mais evasivo e presunçosamente vago este se torna, não deixando de ser, porém, uma noção de lei de "alto nivel", interpretada sempre com referências às tradições, circunstâncias e contextos contemporâneos.

\section{A cidadania como natureza normativa do ser racional}

Os primeiros estóicos definiram a doutrina do mundo como um todo, uma cidade de deuses ${ }^{(17)}$ e homens, em que os primeiros governam os segundos ${ }^{(18)}$. Nesta cidade, todos fazem parte de uma comunidade única porque participam de uma racionalidade comum, isto é, de acordo com a lei natural. O ponto crucial situa-se no argumento que estipula que a natureza normativa dos seres humanos proporciona a cidadania e a comunidade de todos entre si. Mas como consegue então Aurélio reconhecer um ser humano autêntico, ou seja, separado do seu todo? Compreenda-se que as suas ideias cosmopolitas seguem 
a linha aristotélica referente à condição necessária de realização de actividades sociais e à noção imperativa de cidadania como algo convencional (se não houver o desejo de viver isoladamente). A comunidade de seres racionais é assim comparada a um corpo humano, em que cada ser é um membro ou um órgão de um organismo vital comum $^{(19)}$. Quando um homem se afasta da unidade, corta a sua ligação com a razão e com a essência do universo, podendo, todavia, regressar ${ }^{(20)}$. Ainda que os homens desconheçam a sua natureza e concordância com a lei natural da sociedade, a noção de universo, que é sobretudo social, concede-lhes viabilidades para construir uma comunidade de seres racionais. - "Ora o bem de um ser racional é a sociedade.» (M. Aur., 5, 16); "Procuro, então, o que está de acordo com a natureza do ser racional e social." (M. Aur., 5, 29); "A natureza universal é sociável por essência.» (M. Aur., 5, 30).

$\mathrm{Na}$ visão dos estóicos, Alexandre-o-Grande demonstrou a possibilidade antecipada de um estado no qual as diferentes nacionalidades seriam dissipadas pela «irmandade" da cidadania. A ideia de cidadão cosmopolita, entre todos os dogmas estóicos, ganha uma maior praticabilidade no Império Romano. Esta ideia é ainda mais valorizada por homens como Séneca e Marco Aurélio, que consideravam a irmandade universal como algo superior a uma abstracção estéril. O ideal fraternal é o corolário do cosmopolitismo estóico, embora hoje em dia, com a persistência de conflitos externos entre nações e de quezília internas ao nível governamental e administrativo, seja manifestamente considerado como uma utopia comportamental (21). Aurélio, como bom romano, apercebeu-se que a combinação entre a grauitas e humanitas era quase impossível na sua realidade política devido às linhas de tradição e nacionalismo existentes. E, ainda assim, na teoria estóica, compreendeu que havia algo a tirar desta conjugação, nem que fosse uma visão mais inteligível da humanidade, partindo do indivíduo e terminando na comunidade. Marco Aurélio declara claramente que sua cidade é Roma, mas, como homo/anthropos, a sua pátria é o mundo(22).

Por analogia, os verdadeiros seres humanos, os cidadãos cosmopolitas, devem saber qual a sua ligação com o mundo social (incluindo a sua relação com o divino)(23). Segundo esta perspectiva, não se pode fugir das exigências e obrigações do contexto social, sentindo ainda o mérito total da designação de ser humano, isto é, não se pode esperar que a vida como cidadão cosmopolita seja fácil ou livre de qualquer desconforto. Considera-se um "cidadão do mundo" aquele 
que não está somente inserido num estado como uma organização política. Em primeiro lugar, é necessário estar relacionado social e eticamente com os outros concidadãos, em qualquer acontecimento do mundo quotidiano, e, em segundo lugar, entender as condições da vida humana, seja qual for o lugar onde se viva, envolvendo obrigatoriamente o sofrimento e a morte, ou outras situações possíveis como doenças ou exclusão social(24). Assim sendo, o que confere a cidadania não é, em primeira instância, um direito legal ou uma fixação de residência, é a capacidade presente de participar no governo ou na prática judicial, tratando-se acima de tudo de um compromisso simples face ao princípio que a vida em comunidade é a implicação essencial que nos torna um ser racional. O que exige, então, a vida em comunidade no seu plano mais elementar?

Marco Aurélio, num dos seus raros exemplos de argumentos formais ${ }^{(25)}$, relaciona os conceitos de racionalidade, mundo, comunidade e lei. Nas entrelinhas dos seus Pensamentos, repete sempre a sua convicção de que os seres racionais são constituídos para o bem comum, sendo a sociabilidade um bem essencial(26). A sua posição diferenciada por ser imperador de Roma faz com que o seu discurso filosófico tenha um maior desenvolvimento numa dinâmica tripartida de implicações social, política e ética, focando-se nos conceitos de divindade/racionalidade, lei, comunidade, natureza humana e cosmopolitismo. Se se retirar os Pensamentos do seu contexto histórico-político, pode parecer que as ideias aurelianas são ingénuas, ou até, aquilo que Aurélio revogava, retóricas. Nesta temática do cosmopolitismo, é também inegável uma tonalidade melancólica, resignada, pessimista e pouco expectante face às pessoas em geral, que culmina numa tendência utópica. Mas como conseguiu Marco Aurélio produzir esta tonalidade derrotista no cosmopolitismo, que é por si só optimista?

$O$ ideal de principado consegue uma coerência através das ideias estóicas de "constituição mista" e oikeiosis. A noção de comunidade cresce com a influência grega, nomeadamente helenística, que junta o poder individual e o carácter divino do governante. Marco Aurélio teria, por certo, a percepção de que um governante único possuía uma auctoritas especial rumo a um bem comum moderator e rector, abraçando a oikeiosis. Ainda assim, o imperador-filósofo concebe o seu estado imperial como um dever que, por vezes, podia ser um martírio, o que é claramente representativo de uma postura estóica ${ }^{(27)}$. Como o homem mais importante da sua época, Marco Aurélio reconheceu perfeitamente a oikeiosis ${ }^{(28)}$. 
É neste ponto que Aurélio traz algo de novo às ideias cosmopolitas, apesar de se tratar de um aspecto de teoria política que se lê nas entrelinhas quando refere a partilha da razão em comunidade ${ }^{(29)}$. O imperador-filósofo tenta afastar-se das vozes sedutoras do relativismo cultural, as quais são difíceis de suportar quando a filosofia antiga apela à razão. Talvez não seja um argumento suficiente, mas existe matéria que permite lançar bases para uma teoria diferenciada da possibilidade de os seres humanos partilharem uma comunidade. Não se esqueça que, para um estóico, a cidadania faz parte da natureza normativa do ser racional, aproximando o estoicismo e o aristotelismo nas fundações da sociabilidade humana ${ }^{(30)}$.

Esta união entre o estoicismo e o aristotelismo tem a sua melhor expressão no conceito de oikeiosis. Num sentido muito linear, oikeiosis significa uma propensão instintiva do indivíduo para conseguir amar e preservar-se a si e aos que o rodeiam ${ }^{(31)}$, manifestando-se entre os humanos de uma forma natural, pois é algo que decorre da razão. Existe assim um processo de maturidade, em que a cidadania e a sociedade têm também de ser construídas, não sendo somente meros instrumentos. Aliás, para os estóicos em geral, a justiça deriva igualmente da oikeiosis social(32). A oikeiosis aureliana é um bom exemplo da relação sólida que o autor propõe entre ética pessoal e ética social, reconhecendo a virtude (exposta especialmente na sua realização enquanto imperador) como uma prioridade e como uma manifestação de sabedoria. Esta temática expressa as preocupações sócio-políticas de Aurélio, as quais não decaem unicamente no seu status imperial, pois acaba por concretizar efectivamente a racionalidade universal(33).

Há que lembrar que nas ideias cosmopolitas de Marco Aurélio todos os homens são feitos uns para os outros, em patamares iguais, pois a razão universal é comum a todos em plena unicidade ${ }^{(34)}$. E que a comunidade moral dos seres racionais é conseguida através da partiIha de um domínio da razão entre todos os homens, os quais têm, por natureza, obrigações morais entre si. Em termos ideais, esta comunidade é transcendentemente cosmopolita a todas as configurações sócio-políticas existentes ${ }^{(35)}$. Junte-se ainda o aspecto da brevidade vivencial sempre presente em Marco Aurélio, pois todos os homens estão juntos numa comunidade única e sujeitos a leis comuns, ou seja, a lei da razão: "Todas as vezes que imagines que te prejudicam, aplica esta regra: se isso não prejudica a cidade também não me prejudica."(36). As respostas morais devem ser encontradas na individualidade e depois colocadas num ideal de conjunto( $^{(37)}$. 


\section{A vida em comunidade}

O ideal cosmopolita de um mundo perfeito passa necessariamente pelas obrigações naturais e mutuas entre os vários indivíduos, pois é um dever natural servir o conterrâneo, participar nos assuntos cívicos ou retirar-se para a vida contemplativa, ou ainda alternar entre estes estilos de vida. Existe a obrigatoriedade de intervir na política, seja qual for o tipo de governo no poder ${ }^{(38)}$. Cabe então à concórdia (homonoia) reger a amizade e o espírito livre dos seres racionais, o que implica uma coerência de todos os homens unidos num só(39).

$\mathrm{Na}$ vida em comunidade, não se deve temer a mudança, visto que é normal e peremptória na natureza universal. Todos os homens fazem sempre parte de um todo controlado pela natureza, e estão intimamente relacionados de alguma forma uns com os outros ${ }^{(40)}$. Tudo o que acontece ao Homem provém deste todo, estando em consonância com a natureza universal. É, então, do interesse do Homem servir a sua constituição em harmonia com a própria natureza racional e social, aceitando também o seu destino(41).

Marco Aurélio não estipula os deveres dos homens isolada e especificamente, envolve todas as obrigações na natureza social, pois, perante as dificuldades da vida, os homens têm de conseguir por em prática as suas responsabilidades sociais: "[...] entrega-te ao que acreditas ser o melhor [...]" (M. Aur. 4, 1); "É preciso que acompanhes a tua vida acção por acção e, se cada uma delas alcançar o fim próprio, que te declares satisfeito" (M. Aur. 8, 32); "Persiste até que tenhas assimilado bem este pensamento [...]" (M. Aur. 10, 31); "Numerosas são as barreiras e os obstáculos. Mas o espírito e a razão podem atravessar tudo o que as detêm" (M. Aur. 10, 33). Se o Homem faz parte do esquema universal, o seu carácter como ser humano (embora distinto e relevante) é determinado, em última instância, pelas condições da ordem universal: "És isto ou aquilo por essência, ainda que a opinião te faça parecer diferente" (M. Aur. 7, 68); "Ver o que são as coisas nelas próprias, analisá-las na sua matéria, na causa, na relação de finalidade" (M. Aur., 12, 10); "Ver em todas as circunstâncias o que é em si o objecto que produz em ti essa ideia e procurar explicá-lo na sua causa, matéria, fim, duração ao cabo da qual terá necessariamente cessado de existir." (M. Aur., 12, 18).

Aurélio potencia a "unidade" no sentido de ser capaz de relacionar todas as coisas e substâncias no universo ${ }^{(42)}$. O imperador defende esta teoria com a existência dos vários grupos sociais (especialmente 
os mais elevados), comunidades políticas, amizades, alianças económicas, linhagens, assembleias, etc.: "Todos os seres que têm alguma coisa em comum procuram os seus semelhantes [...] observam-se repúblicas, amizades, famílias, reuniões e, em caso de guerra, tratados e tréguas" ${ }^{(43)}$. E é o conceito de "cosmos" que suporta esta unidade, compreendendo o universo como um ser vivo, em substância e alma únicas: "Considera sem cessar que o mundo é como um ser único, contendo uma substância única e uma alma única»(44).

Qual é o propósito da vida moral em comunidade? O imperador-filósofo garante que, por um lado, a benevolência e os bons actos serão os pressupostos da humanidade cosmopolita, e que todos serão mais livres de tais benefícios quando estiverem menos absortos em ansiedade pessoal(45). Por outro lado, Aurélio resolve esta problemática através da educação moral, em conjunto com uma visão estóico-cosmopolita de benevolência: "[...] ao homem feliz atribui-se uma boa parte de boas inclinações de alma, boas tendências, boas acções» ${ }^{(46)}$. O bom cidadão deve submeter-se à lei do seu Estado e servir bem a sua pátria por realizar convenientemente a sua função, pois, ao participar funcionalmente na sua pátria faz um serviço benéfico a toda a humanidade ${ }^{(47)}$ : "Quem foge ao seu amo é desertor. Ora a lei é o nosso amo. Portanto, quem se afasta da lei é um desertor [...] Em suma, recorda-te que, para um cidadão nato, nada o prejudica se não prejudicar a cidade e nada prejudica a cidade se não prejudicar a lei. Portanto, o que não prejudica a lei não prejudica nem a cidade nem o cidadão»(48).

Diante do mundo que o rodeava, é normal que Marco Aurélio enfatizasse os direitos naturais do ser humano em conformidade com as obrigações de bondade, generosidade e tolerância; tal como se diz, noblesse oblige. Esta indulgência potencia o valor intrínseco da comunidade e cidadania normativas porque os homens procuram sempre a companhia de outros: "A boa vontade para os outros seres humanos é distintiva de nós [...] O factor principal na constituição humana é a sociabilidade» ${ }^{(49)}$. Tal filantropia e preocupação social são relevantes hoje em dia para as nossas sociedades, visível, por exemplo, diante das recentes catástrofes nacionais e mundiais.

\section{Igualdade/«interesse comum» e ideologia liberal}

No sentido de encontrar uma aproximação entre as implicações do «interesse comum» da lei natural e do cosmopolitismo, é necessária 
uma análise focalizada dos valores e objectivos que os seres humanos têm de forma natural e racional.

A lei romana alcançou desenvolvimentos consideráveis de Augusto a Alexandre Severo. As influências legais e filosóficas tiveram como veículo a tradição estóica. Marco Aurélio protagoniza o ideal social e político-legal romano, o qual é alcançado através do imperium (símbolo da lei e ordem legal) e da Pax Romana (símbolo universal de paz, estabilidade e ordem sócio-política de status quo)(50). Quando as doutrinas morais dos estóicos consideram os seres racionais como um todo, Aurélio pensa conjuntamente no império como uma forma de união espiritual, não sendo só um símbolo político. O seu cosmopolitismo deriva inteiramente da ideia ética de comunidade entre todos os homens e consegue transformar o ideal estóico de Humanitas no ideal político-legal de Romanitas, ou seja, não se trata de um ideal de vida político-social porque o cosmopolitismo aureliano deve ser enquadrado na realidade do Império Romano. No fundo, este ideal que provém dos filósofos helenísticos como algo remoto torna-se uma convicção forte de uma missão histórica dos Romanos ${ }^{(51)}$.

Marco Aurélio concentra as ideias cosmopolitas na teoria do Estado Universal: "O mundo é como uma cidade. [...] Sê livre e examina as coisas como homem corajoso, como homem razoável, como cidadão, como ser mortal. [...] "OO mundo é apenas mudança, a vida apenas opinião" "(52). O homem tem um fim social, pois nasce naturalmente numa comunidade e nesta encontra o seu termo como ser racional: "Cada ser deve fazer o que está em relação com a sua constituição. [...] Portanto, o carácter que predomina na constituição do homem é a sociabilidade" (M. Aur. 7,55$)$; "O que quer que faça, só ou com um auxiliar, deve sempre visar este fim único: o que é útil à comunidade e está de acordo com ela" (M. Aur. 7, 5); “Não desperdices a parte da vida que te resta a examinar o que faz outrem, a menos que não vises nenhum fim útil à comunidade" (M. Aur. 3, 4, $1)$; «[...] cada ser é levado para o seu fim, por causa do qual e em vista do qual foi constituído" (M. Aur. 5, 16); "[...] vês como subordinou, coordenou; como designou a cada um a sua parte, proporcionada ao seu valor?» (M. Aur. 5, 30). O homem é parte integrante do sistema social e assegura a unidade, tendo uma relação directa ou indirecta com o objectivo social. E, uma vez mais, a cooperação é entendida como uma acção em harmonia com a natureza em comunidade. O imperador aponta uma razão "cívica" e social(53) para estes homens: "[...] é a própria natureza que introduziu este acontecimento no 
mundo, que nele te fez entrar [...] Ora quero o que está de acordo com a natureza do ser racional e social» ${ }^{(54)}$. Enfim, a sua comunidade é efectivamente um estado universal - «Admitido isto, a lei também nos é comum. Admitido isto, somos concidadãos. Admitido isto, fazemos parte de um corpo político comum ${ }^{(55)}$-, pois a unidade formula-se através de um pensamento comum a todos os seres humanos ${ }^{(56)}$.

Para Marco Aurélio, o ideal de comunidade cosmopolita desenvolve-se através do argumento que coloca a razão como elemento compensatório para todos os seres humanos. A lei cosmopolita estipula que todos os indivíduos existem inteiramente num nível de igual respeito e preocupação. Não interessa de onde a pessoa é oriunda, ou seja, a lei cosmopolita não permite (idealmente) diferenças de nacionalidades, grupos sociais ou etnias, tais características levantariam barreiras difíceis de superar entre os concidadãos. Por alguma razão, hoje em dia, existem ainda organizações mundiais e nacionais que salvaguardam a dissolução destes "muros" sociais, pois a humanidade deve ser sempre reconhecida com primazia e respeito ${ }^{(57)}$. Como pode, então, da humanidade surgir a ideia de cidade ou comunidade? Por que não governar seres humanos como criaturas não relacionadas entre si? A ética do cosmopolitismo de Aurélio capacita moralmente o Homem para ser social: nasce para viver e trabalhar conjuntamente, e a sua dignidade está na competência de interagir. Ao respeitar a razão humana, o Homem está também a honrar a sociabilidade da humanidade ${ }^{(58)}$.

A vida moral de um cosmopolita decorre com respeito e preocupação humanas, afastando-se de paixões e bens externos. Será a vida cosmopolita atractiva? Como se define esta natureza de preocupação estóica para com os seres humanos em comunidade? Entenda-se que a atitude cosmopolita não é uma mera emoção, que por variadas vezes toca em pontos como a piedade ou compaixão. No entanto, não existe uma indiferença perante esta linha de emoções, a contenção de sensações somente ajuda a cultivar uma atitude humana de preocupação e benevolência entre concidadãos: “Faz brilhar em ti a simplicidade, o pudor, a indiferença pelo que é intermediário entre a virtude e o vício. Ama a raça humana»(59). Aurélio define um rumo psicológico, uma certa via provisória de pensamento, que permanece na iminência de algum ser humano se tornar um obstáculo às preocupações de todos, não conduzindo directamente ao ódio: "[...] o homem é um ser que nos está muito intimamente ligado, na medida em que Ihes devemos fazer bem e suportá-los»(60). 
Nos Pensamentos de Marco Aurélio, há uma ideia sempre presente: não se é anthropos ${ }^{(61)}$, se se estiver afastado da comunidade, existindo um dever esmagador em servir a sociedade. A lei romana deve muito à influência amplamente conhecida do estoicismo, mas o pensamento liberal também tem que agradecer a esta corrente filosófica antiga. O seu legado para o liberalismo encontra-se na noção de espírito de auto-consciência como um atributo do ser humano, em que o indivíduo é composto de entidade moral e legal. A virtude social é a competência em interagir com a comunidade, partilhando valores e objectivos idênticos e enriquecendo-se mutuamente ${ }^{(62)}$.

Quando se refere que o estoicismo lançou as bases da ideologia liberal, deve ter se em atenção os perigosos anacronismos. O estoicismo parece ser uma corrente filosófica muito liberal devido às suas doutrinas sobre os seres humanos, sobretudo quando se define a concepção de uma comunidade comum em virtude da racionalidade e igualdade entre todos (homens, mulheres, escravos e diferentes etnias), sem quaisquer relações legais em efectivo. Marco Aurélio insiste, por exemplo, na bondade humana como algo divino, mostrando que todos podiam alcançar este plano transcendental ao praticar boas acções em sociedade ${ }^{(63)}$. Um desconhecedor da teologia estóica, com este argumento e de uma forma moderna, poderia separar facilmente a religião da política. Aurélio nada tem de liberalista moderno. O imperador Prefere, aliás, uma posição sem interferência directa e uma manutenção das leis estatais. A sua filosofia define uma linha clara entre o incentivo à dependência, bondade, relações e obrigações mútuas, e o direito do indivíduo rejeitar os princípios estóicos e tolerar tal rejeição. Dentro do seu próprio estoicismo, as doutrinas apelam à verdade, e este aspecto concede-lhe coerência, como se tratasse de um sistema passível de ser rejeitado pelos indivíduos. A defesa do imperador-filósofo prende-se com o princípio que ninguém pode ser prejudicado por outrem pela sua opinião, e assim o bom estóico não tem argumento para ser intolerante ou incriminador ${ }^{(64)}$.

\section{Moralidade estóica e realismo político}

As ideias cosmopolitas de Marco Aurélio comportam uma universalidade plena, mas o imperador não deixa de considerar o Homem como um pequeno elemento do universo: «É preciso que compreendas desde agora de que universo fazes parte [...] e que a tua vida 
está estritamente circunscrita no tempo ${ }^{(65)}$. Ainda que o Homem se lamente e resista perante a comunidade, não deixa de ser um "cidadão do mundo". De maneira idêntica, Aurélio, como romano e ser racional, não podia fugir dos seus deveres cívicos, e, como Imperador, não podia evitar o dever de respeitar, amar, sofrer, perdoar, ensinar e proteger todos aqueles que governava ${ }^{(66)}$. Assim sendo, o entendimento da humanidade e sociabilidade permitiu-lhe uma visão diferente dos seus inimigos - «[...] é fatal desejar, invejar, suspeitar daqueles que te poderiam arrebatar bens ou armar ciladas [...]”(67), evitando cair naquilo que mais temia, a "tirania". O seu cosmopolitismo consegue encontrar meios de negação do ódio, relembrando que a condescendência é mais importante do que os insultos. Por esta via, até os seus inimigos são concidadãos, pois ambos os lados partilham propósitos e objectivos iguais, podendo tratá-los como fins e não como obstáculos no caminho das suas políticas ${ }^{(68)}$.

Diante da admiração estóico-cosmopolita de Aurélio, fica-se maravilhado com tal nobreza e amabilidade para com os ofensores, podendo ser consideradas como mera simpatia ou simplicidade. O próprio imperador apercebe-se disso, mostrando a sua tristeza, ou seja, preocupa-se mais com as limitações da lei humana do que com a sua própria natureza e desejos. A sua filosofia serve de consolo perante o desconforto das realidades políticas de Roma ${ }^{(69)}$.

Volte a salientar-se que esta filosofia universalista de Marco Aurélio tem uma influência directa do cinismo. Um tendência bem presente quando o autor, por força do contexto em que está inserido, utiliza o Império e o seu totalitarismo como substitutos do universalismo, que ainda coincidem com todos os privilégios e particularidades das obrigações do serviço rigoroso dos deveres do Estado. Aurélio entra por várias especulações teóricas ${ }^{(70)}$, mas, se é a natureza que introduz o ser humano no estado universal, qual é, então, o motivo para este poder ser banido? Como seres racionais devem submeter-se à razão e lei do Estado e do governo. O universo é, portanto, um protótipo de estado e de governo, que tem um princípio de comportamento - a submissão(71). Ainda assim, o seu cosmopolitismo torna-se original devido ao seu humanismo político, sentindo-se responsável por todos os homens e pensando sobre todas as formas de soberania antigas ${ }^{(72)}$. A doutrina aureliana que aplica parece ter o desejo utópico de proteger todos aqueles que governa, salvaguardando os seus aspectos culturais e civilizacionais, ou seja, envolver a história do seu principado na ilusão cosmopolita de todos os seres humanos conseguirem alcançar a razão(73). 
Aurélio não consegue uma teoria cosmopolita coesa, pois o seu cosmopolitismo é insuficiente quando tentar comportar todos elementos externos, acabando por reduzir a vida humana a um nível que não é possível avaliá-la no seu total. O imperador interessa-se somente pela capacidade moral do ser humano, menosprezando as outras; e concentra-se nos assuntos da justiça, sem os considerar como tarefas urgentes a cumprir: "A isto exclusivamente: pensamentos conformes à justiça, uma conduta regulada pelo bem social [...]"(74). Nada se superioriza, e tudo parece ter igual valor ${ }^{(75)}$. Parece também não haver a preocupação de aplicar as ideias cosmopolitas num campo governamental efectivo (em actos sociais de cooperação), aceitando tudo passiva e negativamente ${ }^{(76)}$.

Como conclusão, pode mencionar-se que a validade destes ideais cosmopolitas de Marco Aurélio deve ser bem avaliada para servir de contributo profícuo numa discussão política contemporânea. Aqueles que defendem a posição política internacionalista vão buscar obviamente argumentos aos conceitos estóicos, mas estes são muitas vezes meras concepções ético-políticas, sendo necessário algum cuidado para não importar ideias e conceitos incompatíveis.

A humildade, o alto desejo de ser fiel ao dever e a humanidade paciente de Aurélio resultam num tom quase egoísta, mantendo esta tonalidade bem presente durante a estabilidade da dinastia Antonina. O cosmopolitismo é um tema querido pelos Antoninos como forma de potenciar a individualidade diante da realidade das conquistas das várias nações. O imperador-filosófo não se prende a uma filosofia naturalista, segue um ascetismo muito próprio. Marco Aurélio não podia fugir, contudo, ao fluxo social constante de várias nacionalidades ou às complexidades de um vasto império, mostrando-se incapaz de substituir o espírito cosmopolita pelo estatuto provincial(77).

O Helenismo concedeu duas grandes características ao mundo Romano: o individualismo e o cosmopolitismo. Foi, contudo, o ideal cosmopolita que participou na propagação rápida do cristianismo, pois teria sido mais difícil se o mundo Romano estivesse dividido por pequenos estados, além de ser uma ideia igualmente conveniente à ideologia cristã. A noção que um homem tem deveres numa comunidade acarreta também uma ideia filantrópica. Segundo a doutrina estóica, a irrefutável lei natural é igual para todos os indivíduos, procurando-se a virtude e o bem, num sentido quase missionário entre os homens ${ }^{(78)}$. 
A esperança mantém-se nos nossos dias. Continua-se a sonhar com uma ética global, que não tenha origem somente nos processos da globalização. Desde a Antiguidade que as tradições religiosas e os ensinamentos políticos subscrevem esta esperança, por mais vã que seja. Mantém-se o apelo à mente humana em função da universalidade, com verdade e sabedoria. Os incentivos contemporâneos relativos à globalização não deixam de ter este solo filosófico. O exemplo sempre apresentado pelos especialistas modernos é Immanuel Kant, mas este filósofo do "dever" continuou o legado do estoicismo romano ${ }^{(79)}$. Entre a Antiguidade e a contemporaneidade não há uma partilha de cosmologia ou teologia, simplesmente a força da razão e lei natural une os dois mundos. O racionalismo estóico-kantiano é uma mais-valia para a ideia actual de globalização devido à sua ambição em fixar a força da razão, a qual pode ser partilhada por todos em qualquer época ou em qualquer lugar. Tanto Kant como Marco Aurélio propõem um desafio que é simultaneamente nobre e prático. Não se esqueça, todavia, que a base moral dos estóicos é a «humanidade racional" e que a comunidade moral é definida no potencial da razão em cada ser humano. Uma cidadania partilhada por todos é possível porque cada ser racional e moral contém uma porção de divino, de razão(80).

Pode afirmar-se que Marco Aurélio invoca um género de bondade política, como se a associação de todos os seres humanos fosse possível sob qualquer governo, segundo um consenso geral de normas morais. Para os estóicos, a boa cidadania significa ser um "cidadão do mundo", resolvendo os problemas como um todo e como algo «intrinsecamente" viável. Parece que Aurélio não pensa na realidade do Império que governava, pois desinteressa-se das diferenças entre o povo em geral e as alianças locais. De facto, o conhecimento destas situações era tido usualmente com uma pré-condição ou um corolário de habilidade cosmopolita em discernir e respeitar a dignidade da humanidade em cada pessoa. A evolução estóica de um mundo cosmopolita passava também pela definição primária dos termos e conteúdos das alianças dos grupos locais e diferentes identidades ${ }^{(81)}$.

Visto de um ângulo político, as regras universais (como teorias) não operam de forma indiferente? Existe um código moral, racional e moral em Marco Aurélio que expõe "superficialmente" aspectos institucionais e objectivos práticos. Parafraseando a distinção estóica entre o meramente local ou mundano e a comunidade transcendental, Aurélio 
apoia-se em primeiro lugar na aliança moral em vez da forma de governação que praticava, pois a comunidade moral é construída $a b$ origine pela humanidade de todos os seres humanos. Apesar de marcar sua a sabedoria e o compromisso para com a justiça, o imperador-filósofo mostra pouco ou quase nenhuma preocupação pela liberdade política ${ }^{(82)}$. Embora a vida do Império Romano fosse constantemente polarizada entre a opção de participar ou partir em retirada, sentia-se a necessidade de um união ética que juntasse aspectos sociais, cívicos e políticos, em variadas formas. Existiu sempre a tentativa de elevar estruturas imperiais que revitalizassem as políticas locais e urbanas, daí a noção estóica de bem comum ser normalmente interpretada como uma alternativa à actividade cívica e responsabilidade política ${ }^{(83)}$.

Como pode uma filosofia, que relega a indiferença de tudo o que a população normalmente valoriza, incluindo a vida na sua essência, ter marcado o interesse político? Pode uma sociedade moderna encontrar alguma base na doutrina estóica que preza acima de tudo a virtude moral? Não é o estoicismo totalmente incompatível com uma ideologia que torne o bem comum e a credibilidade governativa dependentes (idealmente) da provisão igualitária e distribuição de bens materiais e serviços, oportunidades de emprego, segurança nacional, estado de saúde e muito mais? Por um lado, o estoicismo aureliano pode promover provocações políticas, mostrando a sua doutrina de valor e indiferença, e por outro, bem entendidas as suas ideias cosmopolitas, pode providenciar o antídoto necessário para a sociedade que tende a ficar oprimida devido às diversas pressões sociais.

Mutatis mutandis, da mesma forma que alguns governos actuais têm a intenção de providenciar à população em geral as mesmas oportunidades de bens e serviços, a Antiguidade começou bem cedo a pensar nesta dinâmica liberal e igualitária. Ainda assim, com alguma praticabilidade, é possível estabelecer um forte paradoxo: a sociedade Antiga (sem a teoria estóica) baseava-se em políticas e ideologias dominantes, as quais desacreditavam a ideia que as suas estruturas de poder político deviam preocupar-se com a promoção do bem-estar da população em geral. Talvez não deva ser uma preocupação a ter de uma forma tão determinada, pois os governos actuais, que primam por ter tais objectivos em programas políticos, acabam por ser pouco populares e a população tende a não votar. Sem explorar as razões actuais da existência destas atitudes tépidas, na Antiguidade, conjectura-se que a maioria da população, o Estado e a grande comu- 
nidade/cidadania não possibilitaram a demonstração dos bens intrínsecos, mas sim o valor instrumentista de servir necessidades e desejos de indivíduos e grupos localizados.

Pode ser que, sem os impulsos e as necessidades de bens materiais e serviços, o estoicismo de Marco Aurélio lance o desafio de considerar a racionalidade e convivência mútua não só como valores de uma categoria de "alta ordem", mas também como elementos integrantes da via de sobrevivência dos seres civilizados.

\section{Notas}

(1) BAKER, E., The Political Thought of Plato and Aristotle, New York, 1959, 483-499.

(2) DEVINE, F. E., “Stoicism on the Best Regime», JHI 31/3, 1970, 323-336.

(3) M. Aur. 1, 14 - «[...] ter conhecido graças a ele Trásea, Helvídio, Catão, Díon, Bruto.»; LONG, A. A., "Stoic Communitarianism and Normal Citizenship", Social Philosophy and Policy 24, 2007, 241-261.

(4) SCHOFIELD, M., The Stoic Idea of the City, Cambridge, 1991.

(5) LONG, A. A., "Stoic Communitarianism and Normal Citizenship", Social Philosophy and Policy 24, 2007, 241-261.

(6) Marco Aurélio utiliza "cidadão do Estado».

(7) M. Aur. 3, 11-12.

(8) LONG, A. A., "The Concept of the Cosmopolitan in Greek \& Roman Thought", Daedalus 137/3, 2008, 50-58.

(9) STRIKER, G., "Origins of the Concept of Natural Law", in Essays on Hellenistic Epistemology and Ethics, Cambridge, 1996, 209-220; WATSON, G., "The Law and Stoicism", in A. A. Long, ed., Problems in Stoicism, London, 1971, 216-238.

(10) M. Aur. 5, 6.

(11) FERGUSON, J., Utopias of the Classical World, Ithaca/New York, 1975, 119-120; HADOT, P., La Citadelle Intérieure - Introduction aux Pensées de Marc Aurèle, Paris, 1992, 84-95.

(12) M. Aur. 7, 30.

(13) POLLOCK, F., "Marcus Aurelius and the Stoic Philosophy" Mind 4, 1879, 47-68.

(14) SORABJI, R., Animal Minds and Human Morals, Ithaca, 1993, 145.

(15) SCHOFIELD, M., "Two Stoics Approaches to Justice", in A. Lacks \& M. Schofield, eds., Justice and Generosity: Studies in Hellenistic Social and Political Philosophy, Cambridge, 1995, 199-201.

(16) M. Aur. 4, 3.

(17) Os estóicos, incluindo Marco Aurélio, utilizam os termos "deuses" ou "divindade" que devem ser lidos como uma "racionalidade perfeita". 
(18) Crisipo é o grande defensor da teoria que o lado religioso é o modo perfeito para alcançar o cosmopolitismo, da mesma forma que a conduta correcta do homem para alcançar a perfeição passa por estar inserido numa comunidade de deuses e homens.

(19) M. Aur. 7, 13; 11, 29: um homem que esteja descontente com o que the acontece, age de forma anti social, não faz parte da humanidade; é como uma mão ou um pé que é cortado e jaz ao lado do tronco.

(20) M. Aur. 7,$34 ; 2,16 ; 4,29 ; 12,12$ : a sociedade ou a comunidade pode também ser vista como uma árvore, na qual cada elemento é um ramo.

(21) COOK, W. L., "Fraternal Basis of Socialism", International Journal of Ethics 22, 1911, 69-84.

(22) M. Aur. 6, 44; NYBAKKEN, O. E., "Humanitas Romana", TAPhA 70, 1939, 396-413.

(23) M. Aur. 4, 29; 8, 34; 11, 8 .

(24) O sábio estóico não pode ser menosprezado como ser humano se as circunstâncias exigirem um isolamento social (Sen., Ep. 9, 16).

(25) M. Aur. 4, $1,4$.

(26) M. Aur. 7, 55.

(27) M. Aur. 4, 23.

(28) HADAS, M., "Nationalism to Cosmopolitanism in the Greco-Roman World", JHI 4, 1943, 105-111.

(29) M. Aur. 9, 29.

(30) Aris., Pol. 1, 2, 1253a; MILLER, F. D., Nature, Justice, and Rights in Aristotle's Politics, Oxford, 1995, 32-35.

(31) Cícero fala de "[...] uma fonte de simpatia humana que é natural e mútua entre os homens [...] fazendo com que nenhum humano se considere estranho entre os demais." (Fin. 3, 16-20; 3, 63).

(32) LONG, A. A., "Hierocles on oikeiosis and self-perception", in Stoics Studies, New York, 1996.

(33) ROWE, C. \& SCHOFIELD, M., Greek and Roman Political Thought, Cambridge, 2005, 611-615.

(34) HADOT, P., La Citadelle Intérieure - Introduction aux Pensées de Marc Aurèle, Paris, 1992, 74-84.

(35) COLISH, M. L., The Stoic Tradition from Antiquity to the Early Middle Ages - I. Stoicism in Classical Latin Literature, Leiden/New York, 1985, 38-41.

(36) M. Aur. 5, 22.

(37) FERGUSON, J., Utopias of the Classical World, Ithaca/New York, 1975, 111-117.

(38) COLISH, M. L., The Stoic Tradition from Antiquity to the Early Middle Ages - I. Stoicism in Classical Latin Literature, Leiden/New York, 1985, 38-41.

(39) FERGUSON, J., Utopias of the Classical World, Ithaca/New York, 1975, 143.

(40) M. Aur. 2, 2; 4, 3, 4, 36; 5, 13; 7, 25; 8, 50;12, 23; 10, 6: exemplos de mudanças categóricas no universo e da relação íntima entre os homens. 
(41) M. Aur. 6, 44; 5, 8; 8, 7: exemplifica com os actos de impiedade contra a natureza universal: a injustiça (porque os seres racionais são criados em benefício do próximo), a mentira (porque deforma o conhecimento da natureza real das coisas), e a procura do prazer ou a fuga à dor (porque os homens culpam os deuses pelo bem e pelo mal).

(42) M. Aur. 6, 38.

(43) M. Aur. 9, 9, 2-3.

(44) M. Aur. 4, 40.

(45) M. Aur. 10, 10: Marco Aurélio exemplifica este ponto através do seu corpo militar e confronto contra os Sármatas.

(46) M. Aur., 5, 36. Por mais que sejam bens externos ou triviais, são indispensáveis às crianças.

(47) FERGUSON, J., Utopias of the Classical World, Ithaca/New York, 1975, 120-121.

(48) M. Aur., 10, 25 e 33; respectivamente.

(49) M. Aur., 8, 26; 7, 55.

(50) COURCelle-SeneuIL, J. G., Préparation à l'etude du Droit, Paris, 1887, 99 e 396.

(51) CHROUST, A.-H., "The Function of Law and Justice in the Anciente World and the Middle Ages", JHI 7/3, 1946, 298-320; MOMMSEN, T., History of Rome IV, New York, 1984,201 e 204.

(52) M. Aur. 4, 2-3.

(53) "Cívica" pode ter somente um sentido social, enquanto no sentido político é designada como "razão cívica" ou "razão de Estado".

(54) M. Aur. 4, 29; 5, 29; respectivamente.

(55) M. Aur. 4, 4.

(56) STANTON, G. R., "The Cosmopolitan Ideas of Epictetus and Marcus Aurelius", Phronesis 13/2, 1968, 183-195.

(57) M. Aur. 4, 44.

(58) ROWE, C. \& SCHOFIELD, M., The Cambridge History of Greek and Roman Political Thought, Cambridge, 1991, 597-615.

(59) M. Aur. 8, 31.

(60) M. Aur. 5, 20.

(61) O conceito de anthropos relaciona o homem com uma profissão (epangelia), com uma função, é um ser racional e social.

(62) LONG, A. A., From Epicurus to Epictetus - Studies in Hellenistic and Roman Philosophy, Oxford, 2006, 336-338.

(63) LONG, A. A., Epictetus: a Stoic and Socratic to Life, Oxford, 2002, 261-264.

(64) M. Aur. 8, 56.

(65) M. Aur. 2, 4.

(66) SANDBACH, F. H., The Stoics, London, 1975, 176. 
${ }^{(67)}$ M. Aur. 7, 15.

(68) NUSSBAUM, M. C., "The Worth of Human Dignity: Two Tensions in Stoic Cosmopolitanism", in Philosophy and Power in the Graeco-Roman World, New York, 2002, 31-49.

(69) HENDRICKX, B., "Once Again: Marcus Aurelius, Emperor and Philosopher", Historia 23/2, 1974, 254-256; STANTON, G. R., "Marcus Aurelius, Emperor and Philosopher", Historia 18/5, 1969, 571; NOYEN, P., "Marcus Aurelius, The Greatest Practician of Stoicism", AC 24, 1955, 372-383 e "Divus Marcus, princes prudentissimus et iuris religiosissimus", RIDA 1/3, 1954, 349-371.

(70) STANTON, G. R., "Marcus Aurelius, Emperor and Philosopher», Historia 18/5, 1969, 570-587.

(71) Idem, "The Cosmopolitan Ideas of Epictetus and Marcus Aurelius", Phronesis 13/2, 1968, 183-195.

(72) O racionalismo e o espírito da liberdade dos estóicos, o universalismo rigoroso dos cínicos, o naturalismo dos peripatéticos, a tensão platónica entre a dúvida e a certeza, e o utilitarismo próprio dos epicuristas.

(73) MICHEL, A., Histoire des Doctrines Politiques à Rome, Paris, 1971, 79-82.

(74) M. Aur. 4, 3.

(75) NUSSBAUM, M. C., "The Worth of Human Dignity: Two Tensions in Stoic Cosmopolitanism", in Philosophy and Power in the Graeco-Roman World, New York, 2002, 31-49.

(76) GUAL, G., Introduccion de las Meditaciones, Madrid, 1977, 7-25.

(77) MOORE, C. H., "Individualism and Religion in the Early Roman Empire", HThR 2, 1909, 221-234.

(78) ROLLO, W., "Nationalism and Internationalism in the Ancient World", G\&R 6, 1937, 130-143.

(79) NUSSBAUM, M., The Fragility of Goodness: Luck and Ethics in Greek Tragedy and Philosophy, Cambridge, 1986; NUSSBAUM, M., The Therapy of Desire: Theory and Practise in Hellenistic Ethics, Cambridge, 1993; NUSSBAUM, M., "Kant and Stoic Cosmopolitanism", Interpretation 5, 1997, 1-3.

(80) DALLMAYR, F., "Cosmopolitanism: Moral and Political», Political Theory 31/3, 2003, 421-442.

(81) NUSSBAUM, M., "Citizens of the World" in Cultivating Humanity: a Classical Defense of Reform in Liberal Education, Cambridge, 1997, 52-67.

${ }^{\left({ }^{82}\right)}$ Em contraste com os estóicos, os cosmopolitas modernos marcam um afastamento da participação pública através de uma "virtualidade política".

(83) DALLmAYR, F., "Cosmopolitanism: Moral and Political», Political Theory 31/3, 2003, $421-442$. 